\title{
AKTIVITAS ANTIOKSIDAN EKSTRAK ETANOL KULIT JERUK KINTAMANI (Citrus aurantium L.) DALAM MENURUNKAN KETENGIKAN MINYAK KELAPA
}

\author{
P. Oka Sudiana, I M. Oka Adi Parwata, dan J. Sibarani \\ Program Studi Kimia FMIPA Universitas Udayana, Bukit Jimbaran, Bali \\ *E-mail: putuokasudiana@yahoo.com
}

\begin{abstract}
ABSTRAK
Paper ini membahas penentuan aktivitas antioksidan dan pengaruh penambahan ekstrak etanol kulit buah jeruk kintamani (EEKBJK) dalam menurunkan ketengikan minyak kelapa yang sudah dipanaskan pada suhu $200^{\circ} \mathrm{C}$, $250^{\circ} \mathrm{C}, 300^{\circ} \mathrm{C}$ selama 5 menit kemudian didiamkan selama 3 hari.Kerusakan pada minyak kelapa dilihat dari nilai bilangan peroksida, bilangan asam dan kadar asam lemak bebas. Hasil pengukuran aktivitas antioksidan menunjukkan bahwa $\mathrm{IC}_{50}$ dari EEKBJK sebesar $53,71 \mathrm{mg} / \mathrm{L}$. Hal ini menunjukkan EEKBJK mampu sebagai antioksidan. Penurunan masing-masing bilangan peroksida minyak kelapa dengan penambahan EEKBJK 0,02\% b/v adalah 50,19\%, 31,74\% dan 16,01\%. Penurunan masing-masing bilangan asam minyak kelapa dengan penambahan EEKBJK $0,02 \%$ b/v adalah $29,55 \%, 28,21 \%$ dan $18,42 \%$. Penurunan masing-masing kadar FFA minyak kelapa dengan penambahan EEKBJK 0,02\% b/v adalah $29,55 \%, 28,21 \%$ dan $18,42 \%$.
\end{abstract}

Kata kunci: antioksidan, Jeruk Kintamani, ketengikan, minyak kelapa

\begin{abstract}
This paper discusses the antioxidant activity measurement of ethanol extract of kintamani citrus rind (EEKBJK) and their effects in reducing rancidity of coconut oil that has been heated at $200^{\circ} \mathrm{C}, 250^{\circ} \mathrm{C}, 300^{\circ} \mathrm{C}$ for 5 minutesthen was kept for 3 days. The damage of the coconut oil was known from the values of peroxide number, acid number and free fatty acid level. The result showed that the $\mathrm{IC}_{50}$ of EEKBJK was $53,71 \mathrm{mg} / \mathrm{L}$ indicating that EEKBJK had a high antioxidants activity. The reduction of the peroxide number by addition of $0.02 \% \mathrm{~b} / \mathrm{v}$ of EEKBJK were of $50.19 \%, 31.74 \%$ and $16.01 \%$, respectively. The reduction of the acid numbers by addition of $0.02 \% \mathrm{~b} / \mathrm{v}$ of EEKBJK were of $29.55 \%, 28.21 \%$, and $18.42 \%$ respectively. The FFA levels decreased as much as $29.55 \%, 28.21 \%$, and $18.42 \%$, respectively by the addition $0.02 \% \mathrm{~b} / \mathrm{v}$ of EEKBJK.
\end{abstract}

Keywords: antioxidant, Kintamani Citrus, rancidity, coconut oil

\section{PENDAHULUAN}

Minyak kelapa sering digunakan oleh masyarakat sebagai bahan masakan karena dapat menambah rasa gurih serta merupakan salah satu sumber energi. Minyak kelapa dapat mengalami perubahan aroma maupun cita rasa selama penyimpanan karena terbentuknya senyawa aldehid dan keton yang dapat menyebabkan kerusakan minyak atau yang dikenal dengan ketengikan. Ketengikan sering disebabkan oleh proses oksidasi, proses oksidasi dipercepat dengan adanya sinar matahari atau pemanasan (Aisyah,
2010; Hodzic, 2009). Kerusakan pada minyak kelapa dapat diketahui dari nilai bilangan peroksida, bilangan asam dan kadar FFA (free fatty acid).

Nilai bilangan asam, bilangan peroksida serta kadar FFA (free fatty acid) pada minyak yang melebihi standar SNI menunjukkan oksidasi berkelanjutan, namun rendahnya bilangan asam, bilangan peroksida dan kadar FFA pada minyak kelapa bukan berarti bebas dari oksidasi. Berdasarkan SNI 7381: 2008 minyak kelapa harus memiliki bilangan peroksida dibawah 10 meq/1000g, bilangan asam dibawah 1,5 mg 
$\mathrm{KOH} / \mathrm{g}$ dan kadar FFA (free fatty acid) dibawah $1 \%$.

Reaksi umum oksidasi radikal bebas pada minyakkelapa merupakan reaksi berantai yang selalu menghasilkan radikal bebas baru. Pada tahap pertama atau inisiasi terjadi pembentukan radikal asamlemak yang merupakan suatu senyawa turunan asam lemak yang memiliki sifat sangat reaktif dan kurang stabil karena hilang atau berkurangnya satu atom hidrogen (reaksi 1). Radikal asam lemak pada minyak kelapaakan mengalami reaksi dengan oksigen yang menghasilkan radikal peroksi pada tahap propagasi (reaksi 2). Tahapan selanjutnya radikal peroksi akan merusak asam lemak. Asam lemak yang telah rusak akan menghasilkan hidroperoksida dan radikal asam lemak baru (reaksi 3). Hidroperoksida yang ada memiliki sifat kurang stabil dan akan mengalami proses degradasi yang menghasilkan senyawa seperti aldehida dan keton yang bertanggung-jawab terhadap perubahan rasa dan bau pada makanan berlemak. Tanpa adanya senyawa antioksidan, reaksi oksidasi pada minyak kelapa akan mengalami proses terminasi yang menghasilkan senyawa kompleks bukan radikal melalui reaksi antar radikal bebas (reaksi 4) (Sanjiwani, 2015). Keseluruhan proses tersebut dapat digambarkan sebagai berikut:

Inisiasi:

$\mathrm{RH} \rightarrow \mathrm{R}^{\bullet}+\mathrm{H}^{\bullet}$

(reaksi 1)

Propagasi:

$\mathrm{R}^{\bullet}+\mathrm{O}_{2} \rightarrow \mathrm{ROO}^{\bullet}$

$\mathrm{ROO} \bullet+\mathrm{RH} \rightarrow \mathrm{ROOH}+\mathrm{R}^{\bullet}$

(reaksi 2)

(reaksi 3)

Terminasi:

$\mathrm{ROO}^{\bullet}+\mathrm{ROO}^{\bullet} \rightarrow \mathrm{ROOR}+\mathrm{O}_{2}$

$\mathrm{ROO}^{\bullet}+\mathrm{R}^{\bullet} \rightarrow \mathrm{ROOR}$

(reaksi 4)

(reaksi 5)

$\mathrm{R}^{\bullet}+\mathrm{R}^{\bullet} \rightarrow \mathrm{RR}$

(reaksi 6)

Gambar 1. Reaksi umum radikal bebas

Salah satu buah yang mempunyai kandungan antioksidan adalah jeruk kintamani (Citrus aurantium L.). Daun jeruk kintamani mengandung alkaloid, polisakarida, flavonoid, minyak atsiri. Akar jeruk kintamani mengandung alkaloid, polisakarida, flavonoid dan saponin. Kulit buah mengandung alkaloid, polisakarida, flavonoid, minyak atsiri, fenolik dan saponin (Lagha, 2013).
Sari buah jeruk kintamani mengandung asam askorbat sekitar 20-60 mg per $100 \mathrm{ml}$, sedangkan vitamin-vitamin lainnya adalah vitamin A, tiamin, niasin, riboflavin, asam pentotenat, biotin, asam folat, inositol dan tokoferol.Berdasarkan beberapa penelitian jeruk kintamani (Citrus aurantium L.) mempunyai keunggulan diantaranya kandungan fenolik pada daun dan kulit dapat digunakan sebagai antiradikal, kandungan minyak atsiri dapat digunakan sebagai anti asetylcholinesterase, sedangkan kandungan flavanoidnya mempunyai sifat anti kanker pada sel A549 (Lagha, 2013; Zarrada, 2015). Senyawa metabolit sekunder dari kulit jeruk Kintamani (Citrus aurantium L.) diperoleh dengan metode maserasi dalam bentuk ekstrak etanol (Lagha, 2013).

\section{MATERI DAN METODE}

\section{Bahan}

Bahan yang digunakan dalam penelitian ini adalah minyak kelapa, kulit jeruk buah Kintamani, akuades, etanol $70 \%$, etanol 95\%, $\mathrm{HCl}$, $\mathrm{KOH}$, asam oksalat $0,1000 \mathrm{~N}$, indikator fenolftalein (pp) $1 \%$, KI jenuh, $\mathrm{NaHCO}_{3}, \mathrm{~K}_{2} \mathrm{Cr}_{2} \mathrm{O}_{7}$ $0,0200 \mathrm{~N}, \mathrm{Na}_{2} \mathrm{~S}_{2} \mathrm{O}_{3}$, , indikator amilum $1 \%$, asam asetat glasial, 1,1-difenil-2-pikrilhidrazil (DPPH) dan kloroform.

\section{Peralatan}

Alat yang digunakan dalam penelitian adalah batang pengaduk, pipet volume, aluminium foil, botol kaca bening, spektrofotometer UV-Vis (Shimadzu UV-1800), pipet tetes, kertas saring, kain kasa, gelas beker, bola penghisap karet, termometer, corong, neraca analitik, gelas ukur, oven, buret, statif, labu ukur, stopwatch, ayakan, penangas, blender, pipet ukur, rotatory vacum evaporator dan erlenmeyer.

\section{Cara Kerja \\ Preparasi minyak kelapa}

Minyak kelapa yang digunakan adalah minyak yang dibeli langsung ke pembuat minyak kelapa. Proses penghilangan kotoran padatan dilakukan dengan cara menyaring minyak kelapa tersebut. Minyak kelapa hasil saringan diukur kadar asam lemak bebas (FFA), densitas, bilangan peroksida, viskositas dan bilangan asamnya. Minyak kelapa kemudian dipanaskan pada suhu 
$200^{\circ} \mathrm{C}, 250^{\circ} \mathrm{C}$ dan $300^{\circ} \mathrm{C}$ selama 5 menit sambil diaduk kemudian didinginkan lalu dilakukan pengukuran bilangan asam, viskositas, kadar asam lemak bebas (FFA), densitas dan bilangan peroksida. Minyak kelapa setelah pemanasan didiamkan selama 3 hari di ruangan terbuka kemudian dilakukan pengukuran densitas, viskositas, kadar asam lemak bebas (FFA), bilangan peroksida, dan bilangan asam.

\section{Ekstraksi kulit buah jeruk kintamani}

Sebanyak $800 \mathrm{~g}$ serbuk kulit buah jeruk kintamani kering dimaserasi dengan $1500 \mathrm{~mL}$ etanol dalam gelas beker selama 24 jam dengan beberapa kali pengadukan. Ampas dan filtrat kulit buah jeruk kintamani dipisahkan menggunakan kertas saring. Filtrat kulit buah jeruk kintamani selanjutnya dievaporasi dengan rotatory vacum evaporator untuk menguapkan pelarutnya sehingga diperoleh ekstrak kental etanol dari kulit buah jeruk kintamani kemudian ekstrak ditimbang dan diuji aktivitas antioksidannya dengan DPPH.

\section{Penambahan ekstrak etanol kulit buah jeruk kintamani pada produk minyak kelapa}

Minyak kelapa ditambahkan antioksidan ekstrak etanol kulit buah jeruk kintamani dengan variasi konsentrasi sesuai dengan nilai $\mathrm{IC}_{50}$ yang diperoleh dan dibandingkan dengan minyak kelapa tanpa penambahan ekstrak. Minyak kelapa yang telah ditambahkan ekstrak etanol kulit buah jeruk kintamaniselanjutnya disimpan dalam botol kaca yang bening bertutup kain kasa selama 24 jam pada suhu kamar. Dilakukan pengujian terhadap densitas, viskositas, kadar FFA, bilangan peroksida, dan bilangan asam.

\section{HASIL DAN PEMBAHASAN}

Karakteristik minyak kelapa menurut SNI dan minyak kelapa baru yang digunakan dala penelitian ini dapat dilihat pada Tabel 1. Tabel 1 menunjukkan bahwa karakteristik minyak kelapa baru masih sesuai dengan standar SNI.
Tabel 1. Karakteristik Minyak Kelapa Menurut SNI dan Minyak Kelapa Baru

\begin{tabular}{lll}
\hline Karakteristik & $\begin{array}{l}\text { Minyak } \\
\text { Kelapa } \\
\text { Baru }\end{array}$ & $\begin{array}{l}\text { Minyak KNI 7381 : 2008 } \\
\text { SNapa }\end{array}$ \\
\hline $\begin{array}{l}\text { Densitas } \\
\left(30^{\circ} \mathrm{C}\right)(\mathrm{g} / \mathrm{mL})\end{array}$ & $0,9237 \pm 0,0006$ & $0,920-0,935$ \\
\hline $\begin{array}{l}\text { Viskositas } \\
\text { Kinematik } \\
\left(30^{\circ} \mathrm{C}\right)(\mathrm{cst})\end{array}$ & $\begin{array}{l}12,2965 \pm 0,110 \\
0\end{array}$ & $11,9670-12,5540$ \\
\hline $\begin{array}{l}\text { Bilangan } \\
\text { Peroksida } \\
(\text { meq } \\
\text { peroksida/100 } \\
0 \mathrm{~g})\end{array}$ & $4,7201 \pm 0$ & Maks. 10,0 \\
\hline $\begin{array}{l}\text { Bilangan } \\
\text { Asam } \\
\text { KOH/g) }\end{array}$ & $1,2757 \pm 0$ & $0,8-1,5$ \\
\hline $\begin{array}{l}\text { Kadar FFA } \\
(\%)\end{array}$ & $0,5830 \pm 0$ & Maks $1 \%$ \\
\hline
\end{tabular}

Standar mutu menurut SNI menyebutkan kriteria minyak kelapa yang baik digunakan adalah yang berwarna kuning muda dan jernih, serta baunya normal atau tidak tengik. Minyak kelapa yang rusak akan berwarna coklat, lebih kental, berbusa, berasap serta dihasilkan rasa dan bau yang tidak disukai pada bahan pangan yang digoreng.

Penggunaan suhu tinggi pada minyak kelapa akan mempercepat proses ketengikan yang ditandai dengan tingginya nilai bilangan peroksida, bilangan asam, dan kadar FFA. Hal ini dikarenakan reaksi oksidasi termal dan paparan $\mathrm{O} 2$ yang terjadi pada saat pemanasan atau penggorengan. Hal ini menunjukkan bahwa di dalam minyak kelapa terdapat asam lemak tidak jenuh sehingga asam lemak tidak jenuh dapat bereaksi dengan oksigen dan membentuk suatu senyawa peroksida yang menyebabkan ketengikan.

Karakteristik minyak kelapa setelah dipanaskan pada suhu $200^{\circ} \mathrm{C}, 250^{\circ} \mathrm{C}$ dan $300^{\circ} \mathrm{C}$ dapat dilihat pada Tabel 2 
Tabel 2. Karakteristik Minyak Kelapa Menurut SNI dan Minyak Kelapa Yang Telah Dipanaskan pada suhu $200^{\circ} \mathrm{C}, 250^{\circ} \mathrm{C}$, dan $300^{\circ} \mathrm{C}$

\begin{tabular}{|c|c|c|c|c|}
\hline Karakteristik & $\begin{array}{l}\text { Minyak } \\
\text { Kelapa } \\
\text { Baru } \\
\end{array}$ & $\begin{array}{l}\text { Minyak } \\
\text { Kelapa Suhu } \\
200^{\circ} \mathrm{C} \\
\end{array}$ & $\begin{array}{l}\text { Minyak } \\
\text { Kelapa Suhu } \\
250^{\circ} \mathrm{C} \\
\end{array}$ & $\begin{array}{l}\text { Minyak } \\
\text { Kelapa Suhu } \\
300^{\circ} \mathrm{C} \\
\end{array}$ \\
\hline $\begin{array}{l}\text { Densitas }\left(30^{\circ} \mathrm{C}\right) \\
(\mathrm{g} / \mathrm{mL})\end{array}$ & $\begin{array}{l}0,9237 \pm 0 \\
, 0006\end{array}$ & $\begin{array}{l}0,9247 \pm \\
0,0012 \\
\end{array}$ & $0,9273 \pm 0,0006$ & $0,9307 \pm 0,0006$ \\
\hline $\begin{array}{l}\text { Viskositas } \\
\text { Kinematik }\left(30^{\circ} \mathrm{C}\right) \\
\text { (cst) }\end{array}$ & $\begin{array}{l}12,2965 \pm \\
0,1100\end{array}$ & $13,0566 \pm 0,6523$ & $13,4757 \pm 0,3335$ & $\begin{array}{l}13,7923 \pm \\
0,5226\end{array}$ \\
\hline $\begin{array}{l}\text { Bilangan Peroksida } \\
\text { (meq } \\
\text { peroksida/1000g) }\end{array}$ & $4,7201 \pm 0$ & $13,3593 \pm 1,3611$ & $22,7255 \pm 1,3573$ & $\begin{array}{l}32,7925 \pm \\
0\end{array}$ \\
\hline $\begin{array}{l}\text { Bilangan Asam (mg } \\
\mathrm{KOH} / \mathrm{g})\end{array}$ & $1,2757 \pm 0$ & $\begin{array}{l}3,2282 \pm \\
0,1472 \\
\end{array}$ & $4,9981 \pm 0,1467$ & $6,9211 \pm 0,1463$ \\
\hline Kadar FFA (\%) & $0,5830 \pm 0$ & $\begin{array}{l}1,4753 \pm \\
0,0673\end{array}$ & $2,2841 \pm 0,0670$ & $3,1629 \pm 0,0668$ \\
\hline
\end{tabular}

Tabel 3. Karakteristik Minyak Kelapa Menurut SNI dan Minyak Kelapa Setelah Dipanaskan Yang Didiamkan 3 Hari

\begin{tabular}{|c|c|c|c|c|}
\hline Karakteristik & $\begin{array}{l}\text { Minyak } \\
\text { Kelapa } \\
\text { Baru }\end{array}$ & $\begin{array}{l}\text { Minyak } \\
\text { Kelapa Suhu } \\
200^{\circ} \mathrm{C}\end{array}$ & $\begin{array}{l}\text { Minyak } \\
\text { Kelapa Suhu } \\
250^{\circ} \mathrm{C}\end{array}$ & $\begin{array}{l}\text { Minyak } \\
\text { Kelapa Suhu } \\
300^{\circ} \mathrm{C}\end{array}$ \\
\hline Densitas $\left(30^{\circ} \mathrm{C}\right)(\mathrm{g} / \mathrm{mL})$ & $\begin{array}{l}0,9237 \pm 0 \\
, 0006\end{array}$ & $0,9247 \pm 0,0022$ & $\begin{array}{l}0,9273 \pm \\
0,0008\end{array}$ & $\begin{array}{l}0,9307 \pm \\
0,0008\end{array}$ \\
\hline $\begin{array}{l}\text { Viskositas } \\
\left(30^{\circ} \mathrm{C}\right)(\mathrm{cst})\end{array}$ & $\begin{array}{l}12,2965 \pm \\
0,1100\end{array}$ & $\begin{array}{l}13,1546 \pm \\
0,5626\end{array}$ & $\begin{array}{l}13,5653 \pm \\
0,1486\end{array}$ & $\begin{array}{l}13,8690 \pm \\
0,1708\end{array}$ \\
\hline $\begin{array}{l}\text { Bilangan Peroksida (meq } \\
\text { peroksida/1000g) }\end{array}$ & $4,7201 \pm 0$ & $\begin{array}{l}14,9310 \pm \\
1,3612\end{array}$ & $\begin{array}{l}24,2927 \pm \\
1,3573\end{array}$ & $\begin{array}{l}34,3540 \pm \\
1,3523\end{array}$ \\
\hline $\begin{array}{l}\text { Bilangan Asam } \quad(\mathrm{mg} \\
\mathrm{KOH} / \mathrm{g})\end{array}$ & $1,2757 \pm 0$ & $3,3981 \pm 0,1471$ & $5,4216 \pm 0,1468$ & $\begin{array}{l}7,2586 \pm \\
0,1462\end{array}$ \\
\hline$\%$ FFA $(\%)$ & $0,5830 \pm 0$ & $1,5529 \pm 0,0672$ & $2,4476 \pm 0,0671$ & $\begin{array}{l}3,3171 \pm \\
0,0668\end{array}$ \\
\hline
\end{tabular}

Berdasarkan Tabel 2 diketahui bahwa semakin tinggi suhu yang digunakan untuk memanaskan minyak kelapa maka semakin tinggi pula nilai bilangan peroksida, bilangan asam maupun kadar FFAnya.

Karakteristik minyak kelapa menurut SNI dan minyak kelapa setelah dipanaskanpada suhu $200^{\circ} \mathrm{C}, 250^{\circ} \mathrm{C}, 300^{\circ} \mathrm{C}$ dan didiamkan 3 hari dapat dilihat pada Tabel 3.

Berdasarkan Tabel 3 diketahui bahwa minyak kelapa setelah dipanaskan pada suhu $200^{\circ} \mathrm{C}, 250^{\circ} \mathrm{C}, 300^{\circ} \mathrm{C}$ dan didiamkan 3 hari mengalami kenaikan nilai bilangan peroksida, bilangan asam dan kadar FFA.

\section{Ekstraksi dan Skrining Kulit Buah Jeruk Kintamani}

Serbuk kulit buah jeruk kintamani kering diekstrak menggunakan metode maserasi. Ekstraksi ini menggunakan pelarut etanol sebanyak 1,5 L selama 24 jam. Etanol dipilih sebagai pelarut karena sifatnya yang polar dan mampu mengekstrak berbagai senyawa yang terdapat dalam sampel. Hasil dari ekstraksi berupa filtrat berwarna kuning pekat. Filtrat selanjutnya 
Tabel 4 Hasil Uji Skrining Fitokimia

\begin{tabular}{ccccc}
\hline No. & $\begin{array}{c}\text { Uji } \\
\text { Fitokimia }\end{array}$ & Pereaksi & $\begin{array}{c}\text { Warna } \\
\text { Terbentuk }\end{array}$ & Hasil \\
\hline 1 & $\begin{array}{c}\text { Uji } \\
\text { fenolik }\end{array}$ & $\mathrm{FeCl}_{3}$ & Hijau & + \\
\hline 2 & $\begin{array}{c}\text { Uji } \\
\text { flavonoid }\end{array}$ & $\mathrm{Mg}+\mathrm{HCl}$ pekat & Merah muda & + \\
\hline 3 & $\begin{array}{c}\text { Uji } \\
\text { saponin }\end{array}$ & Uji Busa $+\mathrm{HCl}$ encer & - & + \\
\hline $\begin{array}{c}\text { Uji } \\
\text { steroid / } \\
\text { terpenoid } \\
\text { Uji } \\
\text { alkaloid }\end{array}$ & Liebermann-Burchard & $\begin{array}{c}\text { Hijau } \\
\text { (steroid) }\end{array}$ & + \\
\hline 5 & & Mayer & - & - \\
\hline
\end{tabular}

Keterangan: (+) menandakan positif dan (-) menandakan negatifnya senyawa tersebut di sampel.

dievaporasi dan didapatkan ekstrak kasar sebanyak 45,23 g. Ekstrak kasar kemudian diuji skrining fitokimia dengan hasil seperti yang ditunjukkan pada Tabel 4 di atas.

Skrining fitokimia ekstrak etanol kulit buah jeruk kintamani positif mengandung senyawa golongan fenolik, flavonoid dan steroid.

\section{Penambahan Ekstrak Etanol Kulit Buah Jeruk Kintamani ke Dalam Minyak Yang Sudah Tengik}

\section{Bilangan Peroksida}

Nilai bilangan peroksida minyak kelapa, tanpa dan dengan penambahan ekstrak etanol kulit buah jeruk kintamani dapat dilihat pada Gambar 1 berikut,

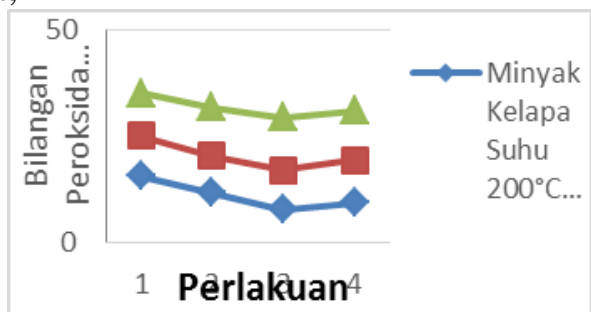

Gambar 1. Bilangan Peroksida Minyak Kelapa Tanpa Ekstrak (1), Dengan Penambahan Ekstrak Etanol Kulit Buah Jeruk Kintamani 0,01\% b/v (2), 0,02\% b/v (3), dan 0,03\% b/v (4).
Berdasarkan Gambar 1, masing-masing minyak kelapa setelah 3 hari ditambahkan ekstrak etanol kulit buah jeruk kintamani sebanyak $0,01 \%$ $\mathrm{b} / \mathrm{v}, 0,02 \% \mathrm{~b} / \mathrm{v}$ dan $0,03 \% \mathrm{~b} / \mathrm{v}$. Minyak kelapa A3 mengalami penurunan bilangan peroksida paling rendah yakni sebesar 50,19\% kemudian penurunan A4 sebesar $40,32 \%$ dan penurunan A2 sebesar $25,16 \%$.

Minyak kelapa B3 mengalami penurunan bilangan peroksida paling rendah yakni sebesar $31,74 \%$ kemudian penurunan B4 sebesar 22,54\% dan penurunan B2 sebesar 19,01\%. Minyak kelapa C3 mengalami penurunan bilangan peroksida paling rendah yakni sebesar $16,01 \%$ kemudian penurunan $\mathrm{C} 4$ sebesar $11,64 \%$ dan penurunan $\mathrm{C} 2$ sebesar $9,34 \%$.

\section{Bilangan Asam}

Bilangan asam minyak kelapa tanpa dan dengan penambahan ekstrak etanol kulit buah jeruk kintamani dapat dilihat pada Gambar 2. Minyak kelapa setelah 3 hari masing-masing ditambahkan ekstrak etanol kulit buah jeruk kintamani sebanyak $0,01 \% \mathrm{~b} / \mathrm{v}, 0,02 \% \mathrm{~b} / \mathrm{v}$ dan $0,03 \%$ b/v. Minyak kelapa A3 mengalami penurunan bilangan asam paling rendah yakni $29,55 \%$ kemudian A4 sebesar $24,80 \%$ dan A2 sebesar $12,76 \%$. 


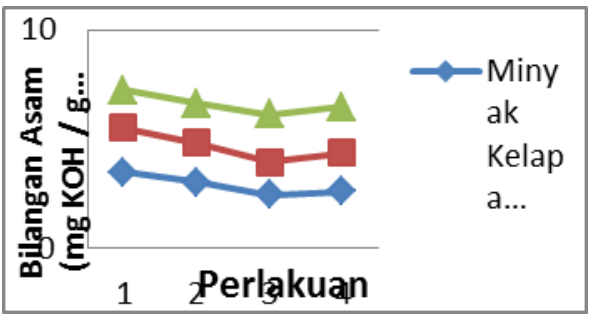

Gambar 2. Bilangan Asam Minyak Kelapa Tanpa Ekstrak (1), Dengan Penambahan Ekstrak Etanol Kulit Buah Jeruk Kintamani $0,01 \%$ b/v (2), $0,02 \% \quad b / v$ (3), dan $0,03 \%$ b/v (4).

Minyak kelapa B3 mengalami penurunan bilangan asam paling rendah yakni $28,21 \%$ kemudian B4 sebesar 20,68\% dan B2 sebesar $12,59 \%$. Minyak kelapa C3 mengalami penurunan bilangan asam paling rendah yakni $18,42 \%$ kemudian C4 sebesar $14,00 \%$ dan C2 sebesar $11,67 \%$.

\section{Kadar FFA}

Kadar FFA minyak kelapa tanpa dan dengan penambahan ekstrak etanol kulit buah jeruk Kintamani dapat dilihat pada Gambar 3 berikut,

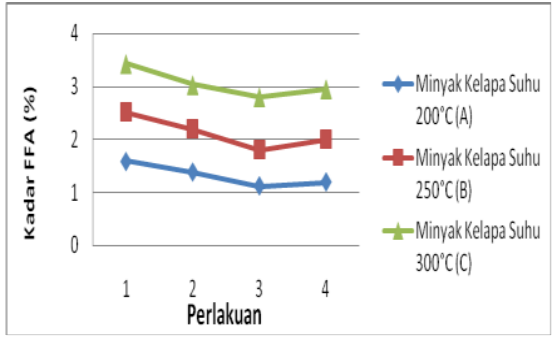

Gambar 3. Kadar FFA Minyak Kelapa Tanpa Ekstrak (1), Dengan Penambahan Ekstrak Etanol Kulit Buah Jeruk Kintamani $0,01 \%$ b/v (2), 0,02\% b/v (3), dan $0,03 \% \mathrm{~b} / \mathrm{v}$ (4).

Berdasarkan Gambar 3, minyak kelapa setelah 3 hari masing-masing ditambahkan ekstrak etanol kulit buah jeruk kintamani sebanyak 0,01\% b/v, 0,02\% b/v dan 0,03\% b/v. Minyak kelapa A3 mengalami penurunan kadar FFA paling rendah yakni $29,55 \%$ kemudian A4 sebesar 24,80\% dan A2 sebesar 12,76\%.
Minyak kelapa B3 mengalami penurunan kadar FFA paling rendah yakni $28,21 \%$ kemudian B4 sebesar 20,68\% dan B2 sebesar 12,59\%. Minyak kelapa C3 mengalami penurunan kadar FFA paling rendah yakni $18,42 \%$ kemudian C4 sebesar 14,00\% dan C2 sebesar 11,67\%.

\section{Mekanisme Pengaruh Ekstrak Etanol Kulit Buah Jeruk Kintamani Terhadap Ketengikan Minyak Kelapa}

Bioaktivitas ekstrak etanol kulit buah jeruk kintamani (Citrus aurantium L.) dalam menurunkan nilai bilangan peroksida, bilangan asam dan kadar FFA pada minyak kelapa diduga disebabkan oleh kandungan senyawa flavonoid. Senyawa flavonoid dapat menyumbangkan salah satu ion hidrogennya $\left(\mathrm{H}^{+}\right)$kepada lipid radikal $\left(\mathrm{R}^{\circ}\right)$ sehingga dapat menghentikan reaksi-reaksi radikal pada tahap selanjutnya, keseluruhan reaksi sebagai berikut (Zheng, 2009):

$$
\begin{aligned}
& \mathrm{R}^{\circ}+\mathrm{O}_{2} \longrightarrow \mathrm{ROO}^{\circ} \\
& \mathrm{ROO}^{\circ}+\mathrm{RH} \longrightarrow \mathrm{ROOH}+\mathrm{R}^{\circ} \\
& \mathrm{R}^{\circ}+\mathrm{FL}-\mathrm{OH} \longrightarrow \mathrm{RH} \text { atall } \mathrm{HL}-0^{\circ}
\end{aligned}
$$

\section{SIMPULAN DAN SARAN}

\section{Simpulan}

Minyak kelapa yang ditambahkan ekstrak etanol kulit buah jeruk kintamani(Citrus aurantium L.) 0,02\% b/v memiliki nilai bilangan peroksida, kadar FFA dan bilangan asam yang rendah. Pada konsentrasi tersebut ekstrak etanol kulit buah jeruk kintamani paling efektif menurunkan ketengikan pada minyak kelapa.

\section{Saran}

Perlu dilakukannya penelitian lebih lanjut menggunakan ekstrak etanol kulit buah jeruk kintamani (Citrus aurantium L.) diatas $0,03 \% \mathrm{~b} / \mathrm{v}$, agar bisa menjelaskan pengaruh kenaikan nilai bilangan asam kadar FFA dan bilangan peroksida pada minyak kelapa yang telah dipanaskan pada suhu $200^{\circ} \mathrm{C}, 250^{\circ} \mathrm{C}$, dan $300^{\circ} \mathrm{C}$ serta didiamkan selama 3 hari yang kemudian telah ditambahkan ekstrak etanol kulit buah jeruk kintamani 0,03\% $\mathrm{b} / \mathrm{v}$. 


\section{UCAPAN TERIMA KASIH}

Penulis mengucapkan terima kasih kepada Prof. Dr. Ir. I.B. Putra Manuaba, M. Phil., Anak Agung Bawa Putra, S.Si., M.Si. dan Sri Rahayu Santi, S.Si., M.Si., Orang tua serta teman-teman angkatan 2012 yang telah membantu dari awal hingga akhir pelaksanaan penelitian ini.

\section{DAFTAR PUSTAKA}

Aisyah, Y. dan Fasya, 2010, Penurunan Angka Peroksida dan Asam Lemak Bebas (FFA) Pada Proses Bleaching Minyak Goreng Bekas Oleh Karbon Aktif Polong Buah Kelor (Moringa Oliefera. Lamk) Dengan Aktivasi NaCl, Jurnal ALCHEMY. 1 (2): 53-103.

Hodzic, Z., H. Pasalic, A. Memisevic, M. Srabovic and M. Polyakovic, 2009, The Influence of Total Phenols Content On Antioxidant Capacity In The Whole Grain Extract, European J. Sci. Res. 28 (2): 471- 477.
Lagha, B.S. and Madani K., 2013, Phenolic Contents and Antioxidant Activity of Orange Varieties (Citrus sinensis L. and Citrus aurantium L.) Cultivated in Algeria, Peels and leaves. Industrial Crops and Products, 50 (1): 723-730.

Sanjiwani, S.N.M., Suaniti, N.M. dan Rustini N.L., 2015, Bilangan Peroksida, Bilangan Asam, dan Kadar FFA Biodiesel Dengan Penambahan Antioksidan dari Kulit Buah Pisang Kepok (Musa paradisiacal Linn.). Jurnal Kimia, 9 (2): 259-266.

Zarrada, K., Amel B. H., Ikbal C., Asma L., Jouda M., Ben J., 2015, Chemical Composition, Fumigant and Anti-acetylcholinesterase activity of The Tunisian Citrus aurantium L. Essential Oils. Industrial Crops and Products. 76 (15): 121-127.

Zheng, W. and Wang S.Y., 2009, Antioxidant Activity And Phenolic Compounds In Selected Herbs. J. Agric.Food Chem. 49 (11): 5165-70. 